\title{
Cerebral oxygenation and hyperthermia
}

\author{
Anthony R. Bain ${ }^{1 *}$, Shawnda A. Morrison ${ }^{2}$ and Philip N. Ainslie ${ }^{1}$ \\ ${ }^{1}$ Centre for Heart, Lung and Vascular Health, University of British Columbia, Okanagan, BC, Canada \\ ${ }^{2}$ Faculty of Professional Studies, Kinesiology, Acadia University, Wolfville, NS, Canada
}

\section{Edited by:}

Patrice Brassard, Laval University,

Canada

\section{Reviewed by:}

Lars Nybo, University of

Copenhagen, Denmark

R. Matthew Brothers, University of

Texas at Austin, USA

\section{${ }^{*}$ Correspondence}

Anthony R. Bain, Faculty of Health and Social Development, University of British Columbia Okanagan, 3333 University Way, Kelowna, BC, V1V IV7, ART360, Canada

e-mail: anthony.bain@ubc.ca
Hyperthermia is associated with marked reductions in cerebral blood flow (CBF). Increased distribution of cardiac output to the periphery, increases in alveolar ventilation and resultant hypocapnia each contribute to the fall in CBF during passive hyperthermia; however, their relative contribution remains a point of contention, and probably depends on the experimental condition (e.g., posture and degree of hyperthermia). The hyperthermia-induced hyperventilatory response reduces arterial $\mathrm{CO}_{2}$ pressure $\left(\mathrm{PaCO}_{2}\right)$ causing cerebral vasoconstriction and subsequent reductions in flow. During supine passive hyperthermia, the majority of recent data indicate that reductions in $\mathrm{PaCO}_{2}$ may be the primary, if not sole, culprit for reduced CBF. On the other hand, during more dynamic conditions (e.g., hemorrhage or orthostatic challenges), an inability to appropriately decrease peripheral vascular conductance presents a condition whereby adequate cerebral perfusion pressure may be compromised secondary to reductions in systemic blood pressure. Although studies have reported maintenance of pre-frontal cortex oxygenation (assessed by near-infrared spectroscopy) during exercise and severe heat stress, the influence of cutaneous blood flow is known to contaminate this measure. This review discusses the governing mechanisms associated with changes in CBF and oxygenation during moderate to severe (i.e., $1.0^{\circ} \mathrm{C}$ to $2.0^{\circ} \mathrm{C}$ increase in body core temperature) levels of hyperthermia. Future research directions are provided.

Keywords: hyperthermia, heat stress, cerebral blood flow, cerebral oxygenation, hemorrhage, syncope

\section{INTRODUCTION}

The dependence to maintain body core temperature within critically functioning limits (i.e., $37 \pm 3^{\circ} \mathrm{C}$ ) has led to seminal thermoregulatory research spanning the past 100 years (e.g., Haldane, 1905; Lindhard, 1910). From this, the capacity to effectively dissipate heat through convective and evaporative means and the concomitant cardiovascular adjustments to maintain thermoregulatory homeostasis has been topic of several extensive literature reviews (e.g., Rowell, 1974; Crandall and González-Alonso, 2010; Johnson and Proppe, 2011). Only in the last decade, however, have we begun to appropriately understand the cerebrovascular adjustments to hyperthermia. The integrative components of cerebrovascular control and ultimately oxygenation, with focus on commonly occurring levels of hyperthermia (i.e., up to $+2^{\circ} \mathrm{C}$ core temperature) form the basis of this review. Adjustments to the three variables germane to cerebral oxygenation, fundamentally the components of the Fick equation; (1) cerebral metabolism, (2) cerebral $\mathrm{O}_{2}$ extraction, and (3) oxygen delivery (cerebral blood flow-CBF), are discussed. We further highlight the implications of cerebral heat balance and oxygenation during hyperthermic exercise, and provide methodological considerations for future work.

\section{CEREBRAL METABOLISM}

The metabolic demand of human cerebral tissue is such that $\sim 20 \%$ of total body oxygen consumption is taken up by the brain, despite only occupying $2-3 \%$ of total body mass. During passive hyperthermia of $1.5^{\circ} \mathrm{C}$ to $2^{\circ} \mathrm{C}$ above resting core temperature, whole body metabolic rate increases by $\sim 25 \%$ (Saxton, 1981). It remains unclear whether cerebral tissue significantly contributes to the rise in whole-body metabolism during passive hyperthermia. For example, the Arrhenius activation law (or Q10, temperature coefficient), which describes the relation of biological activity to changes in temperature, implies that a rise in $2^{\circ} \mathrm{C}$ from $37^{\circ} \mathrm{C}$ should yield an increase in metabolic rate of $\sim 10 \%$, (South, 1958). However, the change in metabolic rate associated with the Q10 effect in vitro may be more sensitive during hypothermia, compared to hyperthermia (Sébert et al., 2003). Nonetheless, several animal preparations have demonstrated that local cerebral or whole-body passive heating yields an increase in cerebral glucose utilization (McCulloch et al., 1982; Mickley et al., 1997) and cerebral metabolic rate $\left(\mathrm{CMRO}_{2}\right)$ by 5 to $10 \%$ per degree Celsius rise in core temperature (Nemoto and Frankel, 1970a,b; Carlsson et al., 1976; Busija et al., 1988). In the dog, $\mathrm{CMRO}_{2}$ was elevated by $21 \%$ at a rectal temperature $\left(\mathrm{T}_{r e}\right)$ of $42.1^{\circ} \mathrm{C}$ compared to baseline ( $\mathrm{T}_{r e}$ of 37.7); however, it began to fall at $43^{\circ} \mathrm{C}$ (Nemoto and Frankel, 1970b). These latter data likely reflect the temperature dependence on critical cellular activity, whereby nucleotide degradation and blood brain barrier disruption (and imminent death if not treated) begins to occur at extreme core temperatures (i.e., $\geqq 42^{\circ} \mathrm{C}$ in the human) (Bynum et al., 1978). The molecular mechanisms that might impact on cerebral metabolism and oxygenation beyond a rise of $3^{\circ} \mathrm{C}$ have not been explored in humans, and are therefore beyond the scope of this review. 
In humans, positron emission tomography measurements during passive heating to roughly $+2{ }^{\circ} \mathrm{C}$ rectal temperature show an increased metabolic rate of glucose in the hypothalamus, thalamus, corpus callosum, cingulate gyrus, and cerebellum (Nunneley et al., 2002). However, in the same study, significant declines in metabolic rate were observed in the caudate, putamen, insula, and posterior cingulum. To date, although regional differences are apparent, no study exists (to our knowledge) in the healthy awake human providing a measure of global cerebral metabolic rate during passive hyperthermia. In healthy humans during exercise, however, Nybo et al., (Nybo et al., 2002a) demonstrated with arterial and jugular venous sampling that cerebral metabolic rate is higher by $\sim 7-8 \%$ when subjects are hyperthermic (see Discussion on Exercise). Whether the confounding factor of exercise precludes the conclusion that hyperthermia alone causes an increase in cerebral metabolism, remains unknown. Still, given the theoretical Q10 (temperature coefficient) considerations, in conjunction with animal studies, human positron emission tomography data and exercise studies, it is likely that hyperthermia (of up to $+3^{\circ} \mathrm{C}$ ) proffers a dose-dependent response to increase cerebral metabolic rate.

\section{OXYGEN EXTRACTION}

Oxygen is transported into cerebral tissue by diffusion, the speed of which is determined by the oxygen conductivity of cerebral tissue. Oxygen conductivity of cerebral tissue is fundamentally determined by the geometry of the capillaries and surrounding tissue (diffusion area and distance), and the tissue metabolism for a given oxygen gradient from the capillary to tissue (Gjedde, 2005). The speed of oxygen transport, or $\mathrm{O}_{2}$ extraction, can therefore be described as being inversely proportional to blood flow (when metabolism is held constant), and directly proportional to metabolism (when flow is held constant), and the surface area between the tissue and capillaries. As CBF, and subsequently $\mathrm{O}_{2}$ delivery is reduced, tissue extraction increases. However, because of the inverse relationship between blood flow and $\mathrm{O}_{2}$ extraction, when $\mathrm{CBF}$ is reduced by $\sim 50-60 \%$, the corresponding increase in $\mathrm{O}_{2}$ extraction (i.e., of 50-60\%) is no longer sufficient to maintain a constant $\mathrm{CMRO}_{2}$ or adequate cerebral oxygenation (Lennox et al., 1935; Gjedde, 2005); i.e., a critical blood flow limit is reached. It follows that this theoretical critical flow limit is altered if metabolism changes; that is, the brain has a reduced critical $\mathrm{CBF}$ reserve for the maintenance of adequate cerebral oxygenation when metabolism $\left(\mathrm{O}_{2}\right.$ demand $)$ is increased. Given the above theoretical considerations, if brain metabolism increases by a liberal $10 \%$ following a $2{ }^{\circ} \mathrm{C}$ increase in tissue temperature, the critical reduction in blood flow to maintain oxygenation would be $\sim 40-50 \%$.

\section{CEREBRAL BLOOD FLOW}

During passive hyperthermia, respiratory and cardiovascular adjustments disrupt the natural coupling between $\mathrm{CMRO}_{2}$ and CBF. A neurogenic mechanism, i.e., cerebral vasoconstriction from increases in sympathetic nerve activity (SNA), has also been suggested to contribute to reductions in CBF during hyperthermia (e.g., Brothers et al., 2009b). Recent work in partitioning the roles of respiratory and cardiovascular mechanisms and considerations for neurogenic control of CBF during passive hyperthermia is discussed next.

\section{RESPIRATORY-ARTERIAL PCO $\left(\mathrm{PaCO}_{2}\right)$}

Hyperthermia in humans (among other species) is accompanied by a hyperventilatory response, and subsequently marked respiratory alkalosis. In 1905, Haldane was the first to describe, "breathing being more deeper and more frequent than usual" when hyperthermic (Haldane, 1905). The magnitude of the hyperventilatory response is highly variable between individuals, and is likely dependent upon the rate and magnitude of rise in skin and core temperature; however, the reflex hyperventilation is not usually pronounced until a threshold increase in core temperature of at least $1^{\circ} \mathrm{C}$ (Barltrop, 1954 and for review see White, 2006). On average, a $1.5-2.0^{\circ} \mathrm{C}$ increase in core temperature during passive heating yields a reduction in end tidal $\mathrm{CO}_{2}\left(\mathrm{PETCO}_{2}\right)$, a validated surrogate for $\mathrm{PaCO}_{2}$ (Brothers et al., 2011a) of $\sim 5-15 \mathrm{mmHg}$ (see Table 1). However, the reported decline in $\mathrm{PaCO}_{2}$ varies considerably for a give increase in core temperature, which is likely governed by whether the external heating (i.e., skin temperature) was continued or attenuated to provide a steady-state core temperature. In some studies, $\mathrm{PaCO}_{2}$ can drop below $20 \mathrm{mmHg}$, and with severe passive heating $\left(\geq 2^{\circ} \mathrm{C}\right)$ pronounced hyperventilation can lead to hypocapnia-induced carpopedal spasms and tetany (Iampietro et al., 1966 and unpublished observations). The exact mechanisms responsible for the hyperventilatory response during hyperthermia in humans have not been fully delineated. It is likely that a medullar integration of skin, and deep tissue temperature, principally hypothalamic temperature (Ingram and Whittow, 1962; Boden et al., 2000), primarily determine the magnitude of hyperventilatory response to hyperthermia. Temperature reception at the carotid bodies may also play an independent role (Zapata et al., 1994). For example, perfusion of warmed blood to the isolated carotid bifurcation elicits a transient hyperventilation in dogs (Bernthal and Weeks, 1939), while bilateral dissection of the carotid nerves mitigates the ventilatory increase to whole body heating in cats (Fadic et al., 1991).

It is well established that $\mathrm{PaCO}_{2}$ is a potent modulator of CBF (Ainslie and Duffin, 2009). At rest, each mmHg change in $\mathrm{PaCO}_{2}$ above and below eupnia yields an approximate $4 \%$ increase and $2 \%$ decrease in CBF, respectively (Willie et al., 2012; and Willie et al., 2014 for review). During passive supine hyperthermia of $+1-1.5^{\circ} \mathrm{C}$ core temperature above resting, a $10-20 \%$ reduction in cerebral blood flow is typically observed (see Figure 1 and Table 1). The role of $\mathrm{PaCO}_{2}$ in the reduction of CBF during hyperthermia remains debatable. Bain et al. (2013) recently demonstrated, using both volumetric and intra-cranial velocity measurements, that global (anterior and posterior) CBF during supine severe $\left(+2^{\circ} \mathrm{C}\right.$ esophageal temperature $)$ hyperthermia is completely restored to normothermic values upon returning $\mathrm{P}_{E T} \mathrm{CO}_{2}$ back to normothermic levels (Figure 2). This finding is notionally corroborated by other studies (Fan et al., 2008; Nelson et al., 2011). It should be noted, however, that although middle cerebral artery (MCAv) and posterior cerebral artery (PCAv) velocities were statistically restored to normothermic values following $\mathrm{P}_{E T} \mathrm{CO}_{2}$ restoration during $+2{ }^{\circ} \mathrm{C}$ hyperthermia in Nelson et al. (2011), they were still 9 and 3\% lower respectively, 
Table 1 | Summary of human cerebral blood flow blood velocities and flow [CBF(v)] measurements during supine passive hyperthermia.

\begin{tabular}{|c|c|c|c|c|c|c|c|c|c|c|}
\hline Authors & Year & $n$ & \multicolumn{2}{|c|}{ Hyperthermia } & $\triangle \mathrm{MAP}$ & $\Delta$ PETCO2 & \multicolumn{4}{|c|}{$\Delta \mathrm{CBF}(\mathrm{v})$} \\
\hline Brothers et al. & $2009 a$ & 9 & $+1.1^{\circ} \mathrm{C} \mathrm{T}_{\mathrm{gi}}$ & $+3.8^{\circ} \mathrm{C}$ & $-1 \mathrm{mmHg}$ & $-4 \mathrm{mmHg}$ & - & - & - & -18 \\
\hline Brothers et al. & $2009 b$ & 7 & $+1.4^{\circ} \mathrm{C} \mathrm{T}_{\mathrm{gi}}$ & $+4.3^{\circ} \mathrm{C}$ & $-1 \mathrm{mmHg}$ & $-6 \mathrm{mmHg}$ & - & - & - & -31 \\
\hline \multirow[t]{2}{*}{ Fan et al. } & 2008 & 10 & $+0.5^{\circ} \mathrm{C} \mathrm{T}_{\mathrm{es}}$ & $+3.7^{\circ} \mathrm{C}$ & $-14 \mathrm{mmHg}$ & $-3 \mathrm{mmHg}$ & - & - & - & -6 \\
\hline & & & $+2.0^{\circ} \mathrm{C} \mathrm{T}_{\mathrm{es}}$ & $+4.8^{\circ} \mathrm{C}$ & $-16 \mathrm{mmHg}$ & $-17 \mathrm{mmHg}$ & - & - & - & -32 \\
\hline Low et al. & 2008 & 9 & $+1.1^{\circ} \mathrm{C} \mathrm{T}_{\mathrm{gi}}$ & $+3.7^{\circ} \mathrm{C}$ & $-2 \mathrm{mmHg}$ & $-3 \mathrm{mmHg}$ & - & - & - & -13 \\
\hline \multirow[t]{2}{*}{ Nelson et al. } & 2011 & 10 & $+0.9^{\circ} \mathrm{C} \mathrm{T}_{\mathrm{gi}}$ & $+3.5^{\circ} \mathrm{C}$ & $0 \mathrm{mmHg}$ & $-2 \mathrm{mmHg}$ & - & - & -10 & -7 \\
\hline & & 8 & $+1.8^{\circ} \mathrm{C} \mathrm{Tgi}_{\mathrm{gi}}$ & $+5.8^{\circ} \mathrm{C}$ & $-2 \mathrm{mmHg}$ & $-15 \mathrm{mmHg}$ & - & - & -23 & -26 \\
\hline Ogoh et al. & 2013 & 12 & $+0.3^{\circ} \mathrm{C} \mathrm{T}_{\mathrm{es}}$ & $+3.8^{\circ} \mathrm{C}$ & $-1 \mathrm{mmHg}$ & $-2 \mathrm{mmHg}$ & -5 & -8 & - & -15 \\
\hline Wilson et al. & 2006 & 15 & $+0.9^{\circ} \mathrm{C} \mathrm{T}_{\mathrm{gi}}$ & $+4.2^{\circ} \mathrm{C}$ & $0 \mathrm{mmHg}$ & $-2 \mathrm{mmHg}$ & - & - & - & $-15^{*}$ \\
\hline
\end{tabular}

Asterisks $\left({ }^{*}\right)$ indicate values estimated from figure representation. $T_{r e}, T_{e s}$, and $T_{g i}$ represent rectal, esophageal, and gastrointestinal temperature respectively. $n$ $=$ sample size. $M A P=$ mean arterial pressure. $P_{E T} C_{2}=$ end-tidal $C_{2}$ partial pressure. ICA = Internal carotid artery blood flow. VA $=$ vertebral artery blood flow. $M C A v=$ middle cerebral artery blood velocity. PCAv $=$ posterior artery blood velocity.

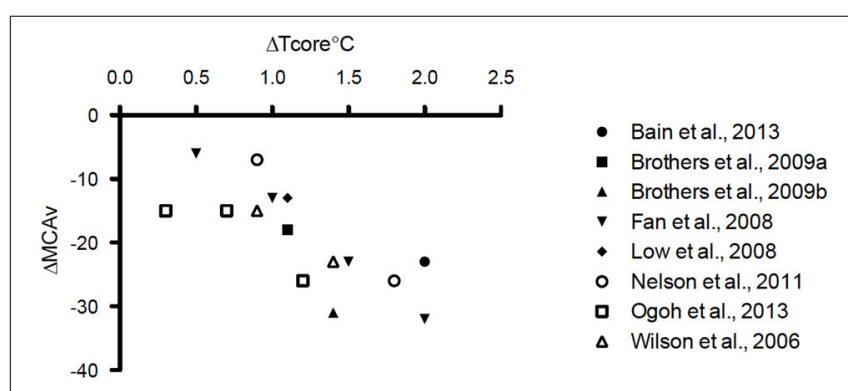

FIGURE 1 | Representation of the reported percent reductions in middle cerebral artery blood velocity (MCAv) ( $x$ axis) as a function of delta core temperature (esophageal, gastrointestinal, or rectal) (y axis) during supine passive hyperthermia up to $+2^{\circ} \mathrm{C}$.

than baseline values. To that end, in opposition of complete CBF restoration following a return to eucapnia, Brothers et al. (2009b) reported that MCAv was only 50\% restored back to normothermic values upon the restoration of $\mathrm{P}_{\mathrm{ET}} \mathrm{CO}_{2}$ during supine hyperthermia. Although difficult to reconcile, these divergent findings may be explained by the variability in "steady-state" $\mathrm{CBF}$ following baseline $\mathrm{P}_{\mathrm{ET}} \mathrm{CO}_{2}$ restoration. For example, although absolute $\mathrm{CO}_{2}$ reactivity appears to be maintained during hyperthermia (Low et al., 2008), the dynamics of the CBF response to eucapnic restoration will in part be determined by the magnitude of the hyperventilation response (and resultant respiratory alkalosis) (Ide et al., 2003). That is, those with a larger hyperventilatory response will likely require a longer time to reach steady-state $\mathrm{CBF}$ values upon restoration of baseline $\mathrm{PaCO}_{2}$ due to a larger extra-cellular $\mathrm{pH}$ gradient. Moreover, sustained hypoventilation may eventually lead to an adaptive response whereby restoration of baseline eucapnia will yield a temporary overshoot in CBF (compared to pre-stimulus values) (Ide et al., 2003). The mechanisms of this CBF overshoot remains unclear, but may involve changes in lactate and bicarbonate (Albrecht et al., 1987; Marder et al., 1990). The transient magnitude of the CBF overshoot therefore probably depends upon the length of time and magnitude of the hypocapnia. It is clear that this can influence "steady-state eucapnic" CBF measures, and may explain the variable conclusions for the role of $\mathrm{PaCO}_{2}$ in reducing CBF during hyperthermia. Nonetheless, taken the most recent data (Nelson et al., 2011; Bain et al., 2013), it is more than likely that $\mathrm{PaCO}_{2}$ explains the majority of the $\mathrm{CBF}$ reduction during passive hyperthermia, at least when subjects are kept in the supine position. Still, future research is warranted to better clarify this role.

In contrast to supine hyperthermia, during upright seated hyperthermia, Fujii et al. (2008) and Ross et al. (2012), found that MCAv is only partially restored back to normothermic levels upon restoration of $\mathrm{P}_{\mathrm{ET}} \mathrm{CO}_{2}$ with the addition of $5 \% \mathrm{CO}_{2}$ to the inspired air. Furthermore, Nelson et al. (2011) found that head up tilt exacerbated the decline in MCAv and PCAv while hyperthermic, in the absence of significant further reductions in $\mathrm{P}_{\mathrm{ET}} \mathrm{CO}_{2}$. It is therefore evident that, during hyperthermia, CBF is declined by increased hydrostatic pressure associated with posture (see Cardiovascular Section), independently of $\mathrm{PaCO}_{2}$.

\section{Do Changes in $\mathrm{PaCO}_{2}$ Alter Tolerance Time to a Simulated Hemorrhage?}

Tolerance time to a simulated hemorrhage is clearly reduced while hyperthermic compared to normothermic (Allan and Crossley, 1972; Wilson et al., 2006; Keller et al., 2009; Brothers et al., 2011b). Reductions in $\mathrm{PaCO}_{2}$ associated with hyperthermia-induced hyperventilation appear to have little influence on the reduced 


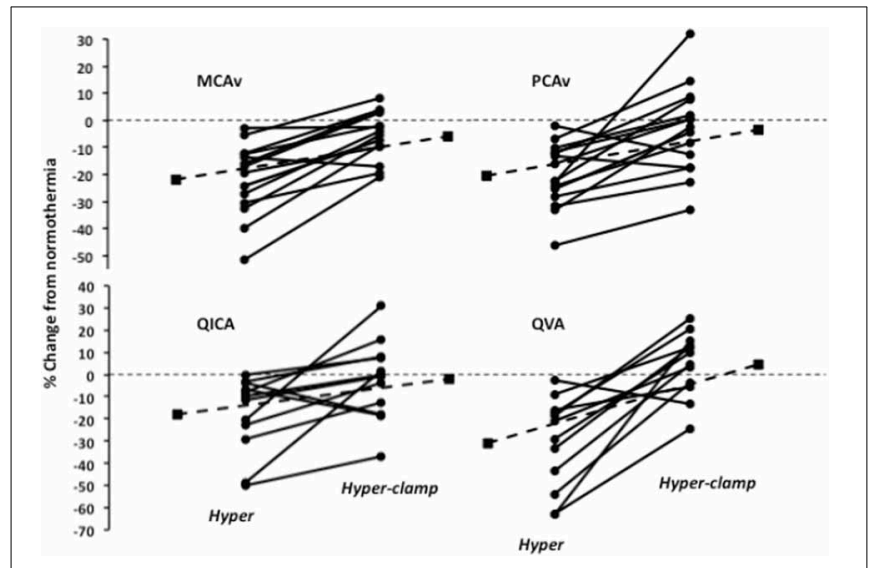

FIGURE 2 | Change in middle cerebral artery blood velocity (MCAv), posterior cerebral artery blood velocity (PCAv), internal carotid artery blood flow (OICA) and vertebral artery blood flow (OVA) following a $2.0^{\circ} \mathrm{C}$ rise in esophageal temperature with and without restoration of end-tidal $\mathbf{C O}_{2}$. Adapted from (Bain et al., 2013).

ability to withstand simulated hemorrhage (Lucas et al., 2013; Pearson et al., 2013). This suggests that cardiovascular adjustments contribute more to tolerance time (i.e., minimum cerebral oxygenation levels before syncope) than baseline CBF during a graded hemorrhage simulation. This notion is supported by findings from our laboratory where tolerance to graded lower body negative pressure was unaltered even when baseline CBF was reduced by $\sim 30 \%$ via administration of indomethacin, independently of changes in $\mathrm{PaCO}_{2}$ (Lewis et al., under review). Such findings may be attributed to the fact that simulated hemorrhage time is typically determined by the time elapsed before ethically low blood pressure levels (usually a SBP of $<80 \mathrm{mmHg}$ ) are attained, rather than syncope itself. A perhaps more ecological stance is the view that a reduction in CBF at baseline, although not effecting tolerance time to simulated hemorrhage, effectively reduces the buffer zone for CBF to change before syncope occurs. As such, when $\mathrm{PaCO}_{2}$ and subsequently $\mathrm{CBF}$, is reduced from hyperthermia, any condition eliciting a faster or larger perturbation in BP (i.e., a period when cerebral autoregulation is less effective) (Tzeng and Ainslie, 2013) compared to graded lower body negative pressure, may pose an increased risk of syncope. It should be noted, however, that dynamic cerebral autoregulation, as indexed by steady-state linear transfer function analysis, appears to be maintained (Low et al., 2009) or perhaps even improved, with hyperthermia (Brothers et al., 2009a).

\section{CARDIOVASCULAR CONTROL}

In order to promote heat loss via evaporative and convective means during severe passive hyperthermia, cutaneous blood flow can increase upwards of 25 -fold (e.g., from $\sim 300$ to $7500 \mathrm{~mL} \cdot \mathrm{min}^{-1}$ ) (Rowell et al., 1969; Rowell, 1986). The large increase in cutaneous vascular conductance is met by concomitant increases in cardiac output (at times up to $13 \mathrm{~mL} \cdot \mathrm{min}^{-1}$ ) (Rowell et al., 1969; Rowell, 1986), accomplished almost exclusively via increases in heart rate. In turn, it is now well accepted that resting $\mathrm{BP}$, and therefore perfusion pressure to the brain during passive, supine hyperthermia, is generally preserved, or only moderately decreased (see Crandall and González-Alonso, 2010 for a comprehensive review on the cardiovascular functioning during hyperthermia). It is interesting to note, however, that BP estimations during passive hyperthermia vary considerably (see Table 1). These variations likely reflect the difficulty in acquiring accurate $\mathrm{BP}$ measurements without measuring it intraarterially during hyperthermia (Ganio et al., 2011). Nonetheless, in contrast to passive supine hyperthermia, it is generally accepted that adequate $\mathrm{BP}$ is not maintained under dynamic hyperthermic conditions, e.g., with an orthostatic challenge or hemorrhage.

Any condition that compromises CBF maintenance inherently increases the risk of syncope/reduction of cerebral oxygenation. As mentioned, tolerance to an orthostatic challenge or simulated hemorrhage is reduced when hyperthermic (Allan and Crossley, 1972; Wilson et al., 2006; Keller et al., 2009; Brothers et al., 2011b). Given that changes $\mathrm{PaCO}_{2}$ seem to play a negligible role in determining tolerance time to a simulated hemorrhage (see section Do changes in $\mathrm{PaCO}_{2}$ alter tolerance time to a simulated hemorrhage?), two key cardiovascular adjustments are likely responsible; (1) the inability to decrease systemic vascular compliance (SVC) (Wilson et al., 2002a; Ganio et al., 2012), and (2) a greater reduction in stroke volume for a given reduction in left ventricular filling pressure (i.e., a leftward shift of the operating point to a steeper portion on the Frank Starling curve) (Wilson et al., 2009). Clearly, the former dictates the latter. When normothermic, it is well established that SVC decreases during a simulated hemorrhage (Murray et al., 1968). Why SVC does not also decrease when hyperthermic, is not entirely understood. However, it is generally accepted that an inhibition of cutaneous vasoconstriction is likely at play (Crandall et al., 2010). An improvement to orthostatic tolerance following acute skin cooling while hyperthermic lends evidence to this hypothesis (Wilson et al., 2002b). The mechanisms of cutaneous vasculature control remains a complex field of study, riddled with redundant mechanistic pathways (for a review see Charkoudian, 2010). Nonetheless, it appears that human physiology places a hierarchy for heat loss during hyperthermia, potentially to the detriment of adequate central blood volume and subsequently $\mathrm{CBF} /$ consciousness.

Dehydration (i.e., $\geq 2 \%$ loss of body mass) often follows prolonged sweating, and is therefore closely tied to hyperthermia. A major cardiovascular consequence of dehydration is a dosedependent decrease in blood volume (Kempton et al., 2009). In turn, dehydration impairs the ability to maintain adequate central blood volumes, and thus CBF during an orthostatic challenge (Harrison et al., 1986; Romero et al., 2011). Carter et al. (2006) demonstrated that the transient reductions in MCAv were larger upon standing from sitting when dehydrated $3.0 \%$ reduction in body mass), compared to euhydrated. Consistent with this finding, Moralez et al. (2012) demonstrated that dehydration $(2.7 \%$ reduction in body mass) exacerbated the reductions in BP and MCAv upon standing following a 10-rep maximum leg press. It is therefore reasonable to assume that when hyperthermia is coupled with dehydration, the ability to maintain adequate CBF is further reduced during orthostatic challenges or hemorrhage.

In contrast to the apparent reduction in CBF with an orthostatic challenge when dehydrated, Fan et al., (Fan et al., 2008) 
demonstrated that when subjects were supine, dehydration $(1.5 \%$ reduction in body mass) increased resting MCAv by $\sim 11 \%$. When subjects were made hyperthermic, however, dehydration appeared to have little or no effect on the reduction in MCAv. It is difficult to reconcile why MCAv was increased with normothermic dehydration compared to euhydration. Increases in CBF during passive supine dehydration may be related to the increased osmolality of extracellular fluid via cerebral cellular shrinkage [i.e., increased concentrations of solutes in the extracellular fluid cause an intra-to extra cellular fluid shift (Kempton et al., 2009)]. In turn, CBF during supine dehydration may be increased to maintain an appropriate ionic milieu for neuronal function. Nonetheless, during passive supine hyperthermia, the marked reductions in MCAv associated with the reduced $\mathrm{PaCO}_{2}$ seem to shadow any effect of dehydration (Fan et al., 2008).

\section{NEUROGENIC CONTROL}

Sympathetic nerve activity in the muscle and skin vasculature is significantly elevated during hyperthermia (Bini et al., 1980; Niimi et al., 1997; Cui et al., 2004; Keller et al., 2006). Hyperthermia decreases vascular conductance of the splanchnic and renal tissue, presumably also via increased SNA (Rowell, 1983). Indeed, it is commonly accepted that the primary mechanism of blood flow redistribution to the cutaneous tissue during hyperthermia is driven by SNA (Rowell, 1990). Whether increased SNA during hyperthermia affects the cerebral vasculature, however, remains speculative. It is well recognized that perivascular adrenergic nerves richly innervate the cerebral arteries, (Edvinsson and Hamel, 2002), while the smooth muscle cells of the arterioles possess both alpha- and beta-adrenergic receptors (Edvinsson, 1982). This suggests that the cerebral vascular has the potential to be mediated by neurogenic factors. In animal models, CBF is reduced with stimulation of the superior cervical ganglion (Heistad et al., 1978; Cassaglia et al., 2008). In humans, unilateral trigeminal ganglion stimulation decreases CBF (Visocchi et al., 1996), while stellate ganglionic blockade increases CBF (Umeyama et al., 1995; Ide et al., 2000). The above animal and human studies support a tonic neurogenic control of CBF. Therefore, several authors have speculated that reductions in CBF during hyperthermia may, in part, be due to increases in cerebral SNA (see Crandall and González-Alonso, 2010 and related references). However, this notion is based primarily by deduction when $\mathrm{PaCO}_{2}$ and MAP cannot explain the full reduction in CBF (see Discussion on the Role of Arterial $\mathrm{PCO}_{2}$ ). Although an attractive hypothesis, several caveats persist to accept that SNA decreases CBF during hyperthermia. First, redundant mechanisms (e.g., dilator agents such as nitric oxide, prostanoids, and histamine) may act to counteract a noradrenaline-induced vasoconstriction of the cerebral vasculature. Specifically, when brain metabolism is elevated (see Discussion on Metabolism and Hyperthermia), a "functional sympatholysis" or "metabolic restraint" might mitigate the influence of SNA (Gross et al., 1983; Busija and Leffler, 1987). This is in agreement with animal studies that report a global increase in CBF to passive hyperthermia (Carlsson et al., 1976; Busija et al., 1988) that cannot be entirely explained by changes in $\mathrm{PaCO}_{2}$. Second, the density of alphaand beta-adrenergic receptors on the cerebral arterioles varies depending on vessel size (Edvinsson, 1982), suggesting that a heterogeneous response, potentially modified by hyperthermia, may exists for a given increase in SNA. Third, the relative influence of SNA on the cerebral vascular seems to be dependent upon levels of blood pressure. That is, sympathetic activation has a larger influence during hypertension, compared to normotension (Bill and Linder, 1976; Edvinsson et al., 1976; and reviewed in Willie et al., 2014). Lastly, the cerebral vasculature has been shown to exhibit a "vasomotor escape" following prolonged maximal SNA stimulation of over $5 \pm 7$ min (Sercobe et al., 1979), suggesting that the influence of SNA on the cerebral vasculature may be dependent on the duration of the stimulation. That CBF has recently been shown to fully recover to normothermic values when $\mathrm{PaCO}_{2}$ is returned to eucapnia (Bain et al., 2013) supports the notion that increases in SNA during hyperthermia proffer a negligible effect on global CBF. Nonetheless, future studies are required to better understand this potential mechanism. Administration of a centrally acting $\alpha 2$-adrenoreceptor agonist (provided no changes in MAP), cervical ganglion block, or measurements of cerebral noradrenaline spillover (Mitchell et al., 2009) during hyperthermia with concomitant measures of global $\mathrm{CBF}$ and maintenance of eupnia, is likely warranted.

\section{CEREBRAL HEAT BALANCE, OXYGENATION, AND EXERCISE}

Human cerebral tissue uses oxygen at a metabolic rate of between 3 to $3.5 \mathrm{mLO}_{2} \cdot 100 \mathrm{~g}$ cerebral tissue ${ }^{-1} \cdot \mathrm{min}^{-1}$ (Lassen, 1985), producing approximately $0.6 \mathrm{j} \mathrm{g}^{-1} \cdot \mathrm{min}^{-1}$ heat, which must then be removed via cerebral circulation (reviewed in: Nybo and Secher, 2004). During hyperthermia, cerebral heat balance is compromised from reductions in CBF (Nybo et al., 2002b) and therefore reductions in convective heat loss (arguably the only avenue for cerebral heat loss). An increased cerebral temperature can impair blood-brain barrier integrity (Watson et al., 2005), particularly when combined with dehydration (Watson et al., 2006). The exact interaction between temperature, blood brain barrier opening and cerebral oxygenation remains obscure.

During hyperthermia exercise capacity is reduced (e.g., Rowell et al., 1966, and for reviews of the potential mechanisms involved see Nybo, 2007 and Cheuvront et al., 2010). Reductions in exercise capacity and a faster onset of fatigue likely stem from interactions of both central and peripheral factors (Nybo and Secher, 2004), including observed alterations in EEG $\alpha / \beta$ arousal levels with greater perceived exertion and decreased motor unit activation (Nybo and Nielsen, 2001; Morrison et al., 2004; Todd et al., 2005; Périard et al., 2011). Decreases in voluntary activation tend to correlate to reductions in MCAv (measured via Doppler ultrasound), but these reductions can be partially restored when breathing a hypercapnic gas mixture to offset changes in ventilation and $\mathrm{P}_{\mathrm{ET}} \mathrm{CO}_{2}$ levels from heat-induced hyperventilation (Ross et al., 2012). However, although preventing hypocapnia during normothermic exhaustive cycling exercise can exhibit increases in MCAv, performance is unchanged (Subudhi et al., 2011). As such, it is likely that a direct effect of increased temperature on CNS and neuromuscular functioning, rather than detriments to cerebral oxygenation, is the primary factor governing decreased exercise capacity while hyperthermic. 


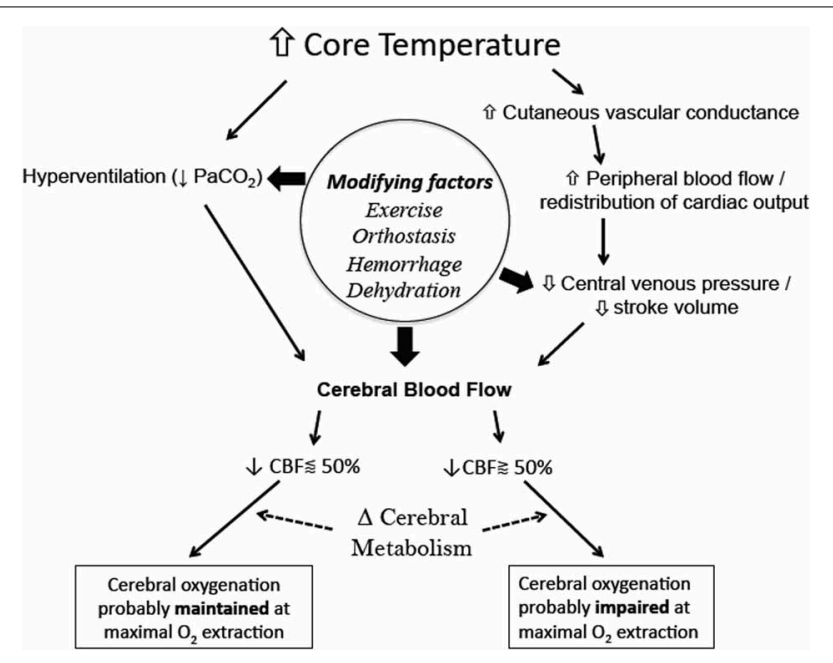

FIGURE 3 | Simplified schematic of the mechanisms and modifying factors involved with reductions in cerebral blood flow and ultimately cerebral oxygenation during whole-body hyperthermia. Global cerebral oxygenation is likely impaired when $\mathrm{CBF}$ is reduced beyond $50 \%$, i.e., a critical blood flow is reached at maximal levels of oxygen extraction.

Changes in cerebral metabolism will alter the theoretical critical blood flow limit, while regional changes in metabolism and blood flow can yield regional differences in cerebral oxygenation.

Examinations of cerebral oxygenation during exercise using near-infrared spectroscopy (NIRS) suggest that cerebral oxygenation is not impaired, including when subjects are passively heated to core temperatures up to $39.5^{\circ} \mathrm{C}$ (Morrison et al., 2009). However, it is now clear that changes in skin blood flow can alter the NIRS-derived oxygenation values (e.g., Davis et al., 2006); thus, data using only this measure must be interpreted with caution. Using the Kety-Schmidt protocol to measure global CBF, Nybo et al. (2002a) and Rasmussen et al. (2010) reported that uncompensable hyperthermic exercise elicited reductions in $\mathrm{CBF}$ by $\sim 18$ and $15 \%$ greater than "normothermic" exercise respectively. Of note, Rasmussen et al. (2010) further estimated cerebral mitochondrial oxygen tension, and found it to be declined by $\sim 5 \mathrm{mmHg}$ during hyperthermic compared to normothermic exercise. This reduction was attributed to the fact that cerebral metabolic rate of oxygen increased by $8 \pm 7 \%$ from the beginning to the end of hyperthermic exercise, while CBF decreased by $15 \%$, and $\mathrm{O}_{2}$ extraction only increased by $7 \%$ (Rasmussen et al., 2010). Given these data, it can be rationalized that cerebral oxygenation is in fact compromised during exhaustive hyperthermic exercise. However, the finding that $\mathrm{O}_{2}$ extraction did not increase sufficiently to maintain mitochondrial oxygenation in the face of moderate increase in metabolic demand (8\%) and reduction in CBF $(15 \%)$, is in contradiction to theoretical considerations (see Oxygen Extraction section). Furthermore, the estimations of mitochondrial oxygen tension are inherently based on several assumptions. For example, the diffusibility of $\mathrm{O}_{2}$ must remain constant (Rasmussen et al., 2007) [supported by the lack of capillary recruitment in rats during hypoxia (Göbel et al., 1989)]; and the potential for cerebral oxygen stores via neuroglobin (Burmester et al., 2000) to preserve mitochondrial oxygenation when $\mathrm{O}_{2}$ availability declines, are also ignored. Nonetheless, these calculations provide the best estimations of cerebral mitochondrial oxygen tension to date in humans. However, it remains that a consensus on global cerebral oxygenation during hyperthermic exercise is difficult to ascertain, and requires further experimentation.

\section{CONCLUSIONS AND FUTURE DIRECTIONS}

The fate of cerebral oxygenation during hyperthermia of up to $+2^{\circ} \mathrm{C}$ core temperature is dependent upon the integrative balance between increases in metabolism and oxygen extraction, with declines in cerebral perfusion pressure from reductions in $\mathrm{PaCO}_{2}$ and increased systemic vascular conductance (Figure 3). When left in the supine position, a $\sim 10 \mathrm{mmHg}$ drop in $\mathrm{PaCO}_{2}$ following a $2^{\circ} \mathrm{C}$ increase in core temperature yields an average CBF reduction by $\sim 25 \%$. At which point, it stands to reason that the global theoretical capacity to increase cerebral $\mathrm{O}_{2}$ extraction is, on average, effective in maintaining cerebral oxygenation, even with an increase in cerebral metabolism of $\sim 10 \%$. On the other hand, the inability of the cardiovascular system to maintain perfusion pressure to the brain during more dynamic conditions (e.g., hemorrhage or orthostatic challenge), coupled with a reduced CBF baseline from reductions in $\mathrm{PaCO}_{2}$, potentiates a condition whereby cerebral oxygenation could be compromised following maximal $\mathrm{O}_{2}$ extraction potential. This fact is clearly evidenced by the reduced tolerance time to simulated hemorrhage, and the increased occurrence of syncope during hyperthermia.

Recent data have collectively provided a salient understanding of cerebral oxygenation during varying degrees of wholebody hyperthermia, however several avenues of experimentation remain. First, it is evident that direct measurements of arterial and cerebral venous blood in humans are required to experimentally verify changes in cerebral metabolism and oxygenation with separate levels of CBF during hyperthermia. Second, albeit inherently difficult to execute, a conclusive study on the role of SNA on CBF during hyperthermia is required. Third, the importance of extra-cranial contamination on NIRS-derived oxygenation values has been highlighted during changes in skin blood flow (Davis et al., 2006) and also where scalp ischemia induced by inflation of a circumferential cranial tourniquet impacted NIRS readings (Davie and Grocott, 2012). Although newer clinically available NIRS monitors use algorithms to subtract light absorption from superficial tissue (e.g., scalp, skin, bone, pia matter) from deeper tissue (Zheng et al., 2013), the utility during hyperthermia and/or exercise remains to be established. Lastly, the interactive role of dehydration, heat acclimatization and certain pathologies (e.g., heart failure, diabetes, autonomic disorders, etc.) on cerebral oxygenation during heat stress should be focus for future work.

\section{REFERENCES}

Ainslie, P. N., and Duffin, J. (2009). Integration of cerebrovascular CO2 reactivity and chemoreflex control of breathing: mechanisms of regulation, measurement, and interpretation. Am. J. Physiol. Regul. Integr. Comp. Physiol. 296, R1473-R1495. doi: 10.1152/ajpregu.91008.2008

Albrecht, R. F., Miletich, D. J., and Ruttle, M. (1987). Cerebral effects of extended hyperventilation in unanesthetized goats. Stroke 18, 649-655. doi: 10.1161/01.STR.18.3.649 
Allan, J. R., and Crossley, R. J. (1972). Effect of controlled elevation of body temperature on human tolerance to $+\mathrm{G} \mathrm{z}$ acceleration. J. Appl. Physiol. 33, $418-420$.

Bain, A. R., Smith, K. J., Lewis, N. C., Foster, G. E., Wildfong, K. W., Willie, C. K., et al. (2013). Regional changes in brain blood flow during severe passive hyperthermia: effects of PaCO2 and extracranial blood flow. J. Appl. Physiol. 115, 653-659. doi: 10.1152/japplphysiol.00394.2013

Barltrop, D. (1954). The relation between body temperature and respiration. J. Physiol. 125, 19-20.

Bernthal, T., and Weeks, W. F. (1939). Respiratory and vasomotor effects of variations in carotid body temperature: a study of the mechanism of chemoceptor stimulation. Am. J. Physiol. 127, 94-105.

Bill, A., and Linder, J. (1976). Sympathetic control of cerebral blood flow in acute arterial hypertension. Acta Physiol. Scand. 96, 114-121. doi: 10.1111/j.17481716.1976.tb10176.x

Bini, G., Hagbarth, K. E., Hynninen, P., and Wallin, B. G. (1980). Thermoregulatory and rhythm-generating mechanisms governing the sudomotor and vasoconstrictor outflow in human cutaneous nerves. J. Physiol. 306, 537-552.

Boden, A. G., Harris, M. C., and Parkes, M. J. (2000). The preoptic area in the hypothalamus is the source of the additional respiratory drive at raised body temperature in anaesthetised rats. Exp. Physiol. 85, 527-537. doi: $10.1017 /$ S0958067000020534

Brothers, R. M., Ganio, M. S., Hubing, K. A., Hastings, J. L., and Crandall, C. G. (2011a). End-tidal carbon dioxide tension reflects arterial carbon dioxide tension in the heat-stressed human with and without simulated hemorrhage. Am. J. Physiol. Regul. Integr. Comp. Physiol. 300, R978-R983. doi: 10.1152/ajpregu.00784.2010

Brothers, R. M., Keller, D. M., Wingo, J. E., Ganio, M. S., and Crandall, C. G. (2011b). Heat-stress-induced changes in central venous pressure do not explain interindividual differences in orthostatic tolerance during heat stress. J. Appl. Physiol. 110, 1283-1289. doi: 10.1152/japplphysiol.00035.2011

Brothers, R. M., Wingo, J. E., Hubing, K. A., and Crandall, C. G. (2009b). The effects of reduced end-tidal carbon dioxide tension on cerebral blood flow during heat stress. J. Physiol. 587, 3921-3927. doi: 10.1113/jphysiol.2009.172023

Brothers, R. M., Zhang, R., Wingo, J. E., Hubing, K. A., and Crandall, C. G. (2009a). Effects of heat stress on dynamic cerebral autoregulation during large fluctuations in arterial blood pressure. J. Appl. Physiol. 107, 1722-1729. doi: 10.1152/japplphysiol.00475.2009

Burmester, T., Weich, B., Reinhardt, S., and Hankeln, T. (2000). A vertebrate globin expressed in the brain. Nature 407, 520-523. doi: 10.1038/35035093

Busija, D. W., and Leffler, C. W. (1987). Eicosanoid synthesis elicited by norepinephrine in piglet parietal cortex. Brain Res. 403, 243-248. doi: 10.1016/00068993(87)90061-8

Busija, D. W., Leffler, C. W., and Pourcyrous, M. (1988). Hyperthermia increases cerebral metabolic rate and blood flow in neonatal pigs. Am. J. Physiol. 255, H343-H346.

Bynum, G. D., Pandolf, K. B., Schuette, W. H., Goldman, R. F., Lees, D. E., WhangPeng, J., et al. (1978). Induced hyperthermia in sedated humans and the concept of critical thermal maximum. Am. J. Physiol. Reg. Integr. Comp. Physiol. 235 R228-R236.

Carlsson, C., Hägerdal, M., and Siesjö, B. K. (1976). The effect of hyperthermia upon oxygen consumption and upon organic phosphates, glycolytic metabolites, citric and cycle intermediates and associated amino acids in rat cerebral cortes. J. Neurochem. 26, 1001-1006. doi: 10.1111/j.1471-4159.1976.tb06484.x

Carter, R., Cheuvront, S. N., Vernieuw, C. R., and Sawka, M. N. (2006), Hypohydration and prior heat stress exacerbates decreases in cerebral blood flow velocity during standing. J. Appl. Physiol. 101, 1744-1750. doi: 10.1152/japplphysiol.00200.2006

Cassaglia, P. A., Griffiths, R. I., and Walker, A. M. (2008). Sympathetic nerve activity in the superior cervical ganglia increases in response to imposed increases in arterial pressure. Am. J. Physiol. Regul. Integr. Comp. Physiol. 294, R1255-R1261. doi: 10.1152/ajpregu.00332.2007

Charkoudian, N. (2010). Mechanisms and modifiers of reflex induced cutaneous vasodilation and vasoconstriction in humans. J. Appl. Physiol. 109, 1221-1228. doi: 10.1152/japplphysiol.00298.2010

Cheuvront, S. N., Kenefick, R. W., Montain, S. J., and Sawka, M. N. (2010), Mechanisms of aerobic performance impairment with heat stress and dehydration. J. Appl. Physiol. 109, 1989-1995. doi: 10.1152/japplphysiol.00367. 2010
Crandall, C. G., and González-Alonso, J. (2010). Cardiovascular function in the heat-stressed human. Acta Physiol. (Oxf.). 199, 407-423. doi: 10.1111/j.17481716.2010.02119.x

Crandall, C. G., Shibasaki, M., and Wilson, T. E. (2010). Insufficient cutaneous vasoconstriction leading up to and during syncopal symptoms in the heat stressed human. Am. J. Physiol. Heart Circ. Physiol. 299, H1168-H1173. doi: 10.1152/ajpheart.00290.2010

Cui, J., Zhang, R., Wilson, T. E., and Crandall, C. G. (2004). Spectral analysis of muscle sympathetic nerve activity in heat-stressed humans. Am. J. Physiol. Heart Circ. Physiol. 286, H1101-H1106. doi: 10.1152/ajpheart.00790.2003

Davie, S. N., and Grocott, H. P. (2012). Impact of extracranial contamination on regional cerebral oxygen saturation: a comparison of three cerebral oximetry technologies. Anesthesiology 116, 834-840. doi: 10.1097/ALN.0b013e31824c00d7

Davis, S. L., Fadel, P. J., Cui, J., Thomas, G. D., and Crandall, C. G. (2006). Skin blood flow influences near-infrared spectroscopy-derived measurements of tissue oxygenation during heat stress. J. Appl. Physiol. 100, 221-224. doi: 10.1152/japplphysiol.00867.2005

Edvinsson, L. (1982). Sympathetic control of cerebral circulation. Trends Neurosci. 5, 425-429. doi: 10.1016/0166-2236(82)90232-6

Edvinsson, L., and Hamel, E. (2002). "Perivascular nerves in brain vessels," in Cerebral Blood Flow and Metabolism, eds L. Edvinsson and D. Krause (Philadelphia: Lippincott Williams and Wilkins), 30-42.

Edvinsson, L., Owman, C., and Siesiö, B. (1976). Physiological role of cerebrovascular sympathetic nerves in the autoregulation of cerebral blood flow. Brain Res. 117, 519-523. doi: 10.1016/0006-8993(76)90760-5

Fadic, R., Larrain, C., and Zapata, P. (1991). Thermal effects on ventilation in cats: participation of carotid body chemoreceptors. Resp. Physiol. 86, 51-63. doi: 10.1016/0034-5687(91)90039-L

Fan, J.-L., Cotter, J. D., Lucas, R. A. I., Thomas, K., Wilson, L., and Ainslie, P. N. (2008). Human cardiorespiratory and cerebrovascular function during severe passive hyperthermia: effects of mild hypohydration. J. Appl. Physiol. 105, 433-445. doi: 10.1152/japplphysiol.00010.2008

Fujii, N., Honda, Y., Hayashi, K., Kondo, N., Koga, S., and Nishiyasu, T. (2008) Effects of chemoreflexes on hyperthermic hyperventilation and cerebral blood velocity in resting heated humans. Exp. Physiol. 93, 994-1001. doi: 10.1113/expphysiol.2008.042143

Ganio, M. S., Brothers, R. M., Lucas, R. A. I., Hastings, J. L., and Crandall, C. G., (2011). Validity of auscultatory and Penaz blood pressure measurements during profound heat stress alone and with an orthostatic challenge. Am. J. Physiol. Regul. Integr. Comp. Physiol. 301, R1510-R1516. doi: 10.1152/ajpregu.00247.2011

Ganio, M. S., Overgaard, M., Seifert, T., Secher, N. H., Johansson, P. I., Meyer, M. A., et al.(2012). Effect of heat stress on cardiac output and systemic vascular conductance during simulated hemorrhage to presyncope in young men. Am. J. Physiol. Regul. Integr. Comp. Physiol. 302, H1756-H1761. doi: 10.1152/ajpheart.00941.2011

Gjedde, A. (2005). The pathways of oxygen in brain. I. Delivery and metabolism of oxygen. Adv. Exp. Med. Biol. 566, 269-275. doi: 10.1007/0-387-26206-7_36

Göbel, U., Klein, B., Schröck, H., and Kuschinsky, W. (1989). Lack of capillary recruitment in the brains of awake rats during hypercapnia. J. Cereb. Blood Flow Metab. 9, 491-499. doi: 10.1038/jcbfm.1989.72

Gross, P. M., Harper, A. M., and Teasdale, G. M. (1983). Interaction of histamine with noradrenergic constrictory mechanisms in cat cerebral arteries and veins. Can. J. Physiol. Pharmacol. 61, 756-763. doi: 10.1139/y83-117

Haldane, J. S. (1905). The influence of high air temperatures. No. I. J. Hyg. 5, 494-513. doi: 10.1017/S0022172400006811

Harrison, M. H., Hill, L. C., Spaul, W. A., and Greenleaf, J. E. (1986). Effect of hydration on some orthostatic and haematological responses to head-up tilt. Eur. J. Appl. Physiol. Occup. Physiol. 55, 187-194. doi: 10.1007/BF00715003

Heistad, D. D., Marcus, M. L., and Gross, P. M. (1978). Effects of sympathetic nerves on cerebral vessels in dog, cat, and monkey. Am. J. Physiol. 235, H544-H552.

Iampietro, P. F., Fiorica, V., Higgins, E. A., Mager, M., and Goldman, R. F. (1966). Exposure to heat: comparison of responses of dog and man. Int. J. Biometeorol. 10, 175-185. doi: 10.1007/BF01426864

Ide, K., Boushel, R., Sørensen, H. M., Fernandes, A., Cai, Y., Pott, F., et al.(2000). Middle cerebral artery blood velocity during exercise with beta- 1 adrenergic and unilateral stellate ganglion blockade in humans. Acta Physiol. Scand. 170, 33-38. doi: 10.1046/j.1365-201x.2000.00757.x 
Ide, K., Eliasziw, M., and Poulin, M. J. (2003). Relationship between middle cerebral artery blood velocity and end-tidal PCO2 in the hypocapnic-hypercapnic range in humans. J. Appl. Physiol. 95, 129-137. doi: 10.1152/japplphysiol.01186

Ingram, D. L., and Whittow, G. C. (1962). The effect of heating the hypothalamus on respiration in the ox (Bos taurus). J. Physiol. 163, 200-210.

Johnson, J. M., and Proppe, D. W. (2011). Cardiovascular adjustments to heat stress. Comp. Physiol. doi: 10.1002/cphy.cp040111

Keller, D. M., Cui, J., Davis, S. L., Low, D. A., and Crandall, C. G. (2006). Heat stress enhances arterial baroreflex control of muscle sympathetic nerve activity via increased sensitivity of burst gating, not burst area, in humans. J. Physiol. 573, 445-451. doi: 10.1113/jphysiol.2006.108662

Keller, D. M., Low, D. A., Wingo, J. E., Brothers, R. M., Hastings, J., Davis, S. L., et al. (2009). Acute volume expansion preserves orthostatic tolerance during whole-body heat stress in humans. J. Physiol. 587, 1131-1139. doi: 10.1113/jphysiol.2008.165118

Kempton, M. J., Ettinger, U., Schmechtig, A., Winter, E. M., Smith, L., McMorris, T., et al. (2009). Effects of acute dehydration on brain morphology in healthy humans. Hum. Brain Mapp. 30, 291-298. doi: 10.1002/hbm.20500

Lassen, N. A. (1985). Normal average value of cerebral blood flow in younger adults is $50 \mathrm{ml} / 100 \mathrm{~g} / \mathrm{min}$. J. Cereb. Blood Flow Metab. 5, 347-349. doi: $10.1038 / \mathrm{jcbfm} .1985 .48$

Lennox, W. G., Gibbs, F. A., and Gibbs, E. L. (1935). Relationship of unconsciousness to cerebral blood flow and to anoxemia. Arch. Neurol. Psychiatry 34, 1001. doi: 10.1001/archneurpsyc.1935.02250230073006

Lindhard, J. (1910) "Investigations into the conditions governing the temperature of the body," in Danmark-ekspeditionen til Gronlands Nordostkyst 1906-1908, ed L. Mylius-Erichsen (Kobenhavn: Bianco Lunos Bogtrykkeri), 3-53.

Low, D. A., Wingo, J. E., Keller, D. M., Davis, S. L., Cui, J., Zhang, R., et al. (2009). Dynamic cerebral autoregulation during passive heat stress in humans. Am. J. Physiol. Regul. Integr. Comp. Physiol. 296, R1598-R1605. doi: 10.1152/ajpregu.90900.2008

Low, D. A., Wingo, J. E., Keller, D. M., Davis, S. L., Zhang, R., and Crandall, C. G. (2008). Cerebrovascular responsiveness to steady-state changes in end-tidal CO2 during passive heat stress. J. Appl. Physiol. 104, 976-981. doi: 10.1152/japplphysiol.01040.2007

Lucas, R. A. I., Pearson, J., Schlader, Z. J., and Crandall, C. G. (2013). Hypercapniainduced increases in cerebral blood flow do not improve lower body negative pressure tolerance during hyperthermia. Am. J. Physiol. Regul. Integr. Comp. Physiol. 305, R604-R609. doi: 10.1152/ajpregu.00052.2013

Marder, J., Eylath, U., Moskovitz, E., and Sharir, R. (1990). The effect of heat exposure on blood chemistry of the hyperthermic rabbit. Comp. Biochem. Physiol. A Comp. Physiol. 97, 245-247. doi: 10.1016/0300-9629(90)90179-V

McCulloch, J., Savaki, H. E., Jehle, J., and Sokoloff, L. (1982). Local cerebral glucose utilization in hypothermic and hyperthermic rats. J. Neurochem. 39, 255-258. doi: 10.1111/j.1471-4159.1982.tb04729.x

Mickley, G. A., Cobb, B. L., and Farrell, S. T. (1997). Brain hyperthermia alters local cerebral glucose utilization: a comparison of hyperthermic agents. Int. J. Hyperthermia 13, 99-114. doi: 10.3109/02656739709056434

Mitchell, D., Lambert, G., Secher, N., Raven, P., Van Lieshout, J., and Esler, M. (2009). Jugular venous overflow of noradrenaline from the brain: a neurochemical indicator of cerebrovascular sympathetic nerve activity in humans. J. Physiol. 587, 2589-2597. doi: 10.1113/jphysiol.2008.167999

Moralez, G., Romero, S. A., Rickards, C. A., Ryan, K. L., Convertino, V. A., and Cooke, W. H. (2012). Effects of dehydration on cerebrovascular control during standing after heavy resistance exercise. J. Appl. Physiol. 112, 1875-1883. doi: 10.1152/japplphysiol.01217.2011

Morrison, S., Sleivert, G. G., and Cheung, S. S. (2004). Passive hyperthermia reduces voluntary activation and isometric force production. Eur. J. Appl. Physiol. 91, 729-736. doi: 10.1007/s00421-004-1063-z

Morrison, S. A., Sleivert, G. G., Neary, J. P., and Cheung, S. S. (2009). Prefrontal cortex oxygenation is preserved and does not contribute to impaired neuromuscular activation during passive hyperthermia. Appl. Physiol. Nutr. Metab. 34, 66-74. doi: 10.1139/H08-139

Murray, R. H., Thompson, L. J., Bowers, J. A., and Albright, C. D. (1968). Hemodynamic effects of graded hypovolemia and vasodepressor syncope induced by lower body negative pressure. Am. Heart J. 76, 799-811. doi: 10.1016/0002-8703(68)90266-4

Nelson, M. D., Haykowsky, M. J., Stickland, M. K., Altamirano Diaz, L. A., Willie, C. K., Smith, K. J., et al. (2011). Reductions in cerebral blood flow during passive heat stress in humans: partitioning the mechanisms. J. Physiol. 589, 4053-4064. doi: 10.1113/jphysiol.2011.212118

Nemoto, E. M., and Frankel, H. M. (1970a). Cerebral oxygenation and metabolism during progressive hyperthermia. Am. J. Physiol. 219, 1784-1788.

Nemoto, E. M., and Frankel, H. M. (1970b). Cerebrovascular response during progressive hyperthermia in dogs. Am. J. Physiol. 218, 1060-1064.

Niimi, Y., Matsukawa, T., Sugiyama, Y., Shamsuzzaman, A. S., Ito, H., Sobue, G., et al. (1997). Effect of heat stress on muscle sympathetic nerve activity in humans. J. Auton. Nerv. Syst. 63, 61-67. doi: 10.1016/S0165-1838(96)00134-8

Nunneley, S. A., Martin, C. C., Slauson, J. W., Hearon, C. M., Nickerson, L. D., and Mason, P. A. (2002). Changes in regional cerebral metabolism during systemic hyperthermia in humans. J. Appl. Physiol. 92, 846-851. doi: 10.1152/japplphysiol.00072.2001

Nybo, L. (2007). Exercise and heat stress: cerebral challenges and consequences. Prog. Brain Res. 162, 29-43. doi: 10.1016/S0079-6123(06)62003-7

Nybo, L., Møller, K., Volianitis, S., Nielsen, B., and Secher, N. H. (2002a). Effects of hyperthermia on cerebral blood flow and metabolism during prolonged exercise in humans. J. Appl. Physiol. 93, 58-64. doi: 10.1152/japplphysiol.00049.2002

Nybo, L., and Nielsen, B. (2001). Hyperthermia and central fatigue during prolonged exercise in humans. J. Appl. Physiol. 91, 1055-1060.

Nybo, L., and Secher, N. H. (2004). Cerebral perturbations provoked by prolonged exercise. Prog. Neurobiol. 72, 223-261. doi: 10.1016/j.pneurobio.2004.03.005

Nybo, L., Secher, N. H., and Nielsen, B. (2002b). Inadequate heat release from the human brain during prolonged exercise with hyperthermia. J. Physiol. 545, 697-704. doi: 10.1113/jphysiol.2002.030023

Ogoh, S., Sato, K., Okazaki, K., Miyamoto, T., Hirasawa, A., Morimoto, K., et al. (2013). Blood flow distribution during heat stress: cerebral and systemic blood flow. J. Cereb. Blood Flow Metab. 33, 1915-1920. doi: 10.1038/jcbfm.2013.149

Pearson, J., Ganio, M. S., Lucas, R. A. I., Babb, T. G., and Crandall, C. G. (2013). Heat stress does not augment ventilatory responses to presyncopal limited lower body negative pressure. Exp. Physiol. 98, 1156-1163. doi: 10.1113/expphysiol.2013.072082

Périard, J. D., Caillaud, C., and Thompson, M. W. (2011). Central and peripheral fatigue during passive and exercise-induced hyperthermia. Med. Sci. Sports Exerc. 43, 1657-1665. doi: 10.1249/MSS.0b013e3182148a9a

Rasmussen, P., Dawson, E.A., Nybo, L., van Lieshout, J.J., Secher, N.H., and Gjedde, A. (2007). Capillary-oxygenation- level-dependent near-infrared spectrometry in frontal lobe of humans. J. Cereb. Blood Flow Metab. 27, 1082-1093. doi: 10.1038/sj.jcbfm.9600416

Rasmussen, P., Nybo, L., Volianitis, S., Møller, K., Secher, N. H., and Gjedde, A. (2010). Cerebral oxygenation is reduced during hyperthermic exercise in humans. Acta Physiol. (Oxf.). 199, 63-70. doi: 10.1111/j.17481716.2010.02084.x

Romero, S. A., Moralez, G., Rickards, C. A., Ryan, K. L., Convertino, V. A., Fogt, D. L., et al. (2011). Control of cerebral blood velocity with furosemideinduced hypovolemia and upright tilt. J. Appl. Physiol. 110, 492-498. doi: 10.1152/japplphysiol.01060.2010

Ross, E. Z., Cotter, J. D., Wilson, L., Fan, J.-L., Lucas, S. J. E., and Ainslie, P. N. (2012). Cerebrovascular and corticomotor function during progressive passive hyperthermia in humans. J. Appl. Physiol. 112, 748-758. doi: 10.1152/japplphysiol.00988.2011

Rowell, L. B. (1974). Human cardiovascular adjustments to exercise and thermal stress. Physiol. Rev. 54, 75-159.

Rowell, L. B. (1983). "Chap 27, Cardiovascular adjustments to thermal stress," in Handbook of Physiology, Section 2, eds F. M. Abbound and J. T. Shepherd (Bethesda, Md: American Physiological Society), 967-1023.

Rowell, L. B. (1986). Human Circulation: Regulation During Physical Stress. New York, NY: Oxford University Press

Rowell, L. B. (1990). Hyperthermia: a hyperadrenergic state. Hypertension 15, 505-507. doi: 10.1161/01.HYP.15.5.505

Rowell, L. B., Brengelmann, G. L., and Murray, J. A. (1969). Cardiovascular responses to sustained high skin temperature in resting man. J. Appl. Physiol. 27, 673-680.

Rowell, L. B., Marx, H. J., Bruce, R. A., Conn, R. D., and Kusumi, F. (1966). Reductions in cardiac output, central blood volume, and stroke volume with thermal stress in normal men during exercise. J. Clin. Invest. 45, 1801-1816. doi: $10.1172 /$ JCI105484

Saxton, C. (1981). Effects of severe heat stress on respiration and metabolic rate in resting man. Aviat. Space Environ. Med. 52, 281-286. 
Sébert, P., Kervran, C., and L'Her, E. (2003). Temperature sensitivity of glycolysis during sepsis. Crit. Care Med. 31, 246-249. doi: 10.1097/00003246-20030100000038

Sercobe, R., Lacombe, P., Aubineau, P., Mamo, H., Pinard, E., Reynier-Rebuffel, A. M., et al. (1979). Is there an active mechanism limiting the influence of the sympathetic system on the cerebral vascular bed? Evidence for vasomotor escape from sympathetic stimulation in the rabbit. Brain Res. 164, 81-102. doi: 10.1016/0006-8993(79)90008-8

South, F. E. (1958). Rates of oxygen consumption and glycolysis of ventricle and brain slices, obtained from hibernating and non-hibernating mammals, as function of temperature. Physiol. Zool. 31, 6-15.

Subudhi, A. W., Olin, J. T., Dimmen, A. C., Polaner, D. M., Kayser, B., and Roach, R. C. (2011). Does cerebral oxygen delivery limit incremental exercise performance? J. Appl. Physiol. 111, 1727-1734. doi: 10.1152/japplphysiol.00569.2011

Todd, G., Butler, J. E., Taylor, J. L., and Gandevia, S. C. (2005). Hyperthermia: a failure of the motor cortex and the muscle. J. Physiol. 563, 621-631. doi: 10.1113/jphysiol.2004.077115

Tzeng, Y. C., and Ainslie, P. N. (2013). Quantification of cerebral hemodynamics. Eur. J. Appl. Physiol. 113, 2869-2870. doi: 10.1007/s00421-013-2719-3

Umeyama, T., Kugimiya, T., Ogawa, T., Kandori, Y., Ishizuka, A., and Hanaoka, K. (1995). Changes in cerebral blood flow estimated after stellate ganglion block by single photon emission computed tomography. J. Auton. Nerv. Syst. 50, 339-346. doi: 10.1016/0165-1838(94)00105-S

Visocchi, M., Chiappini, F., Cioni, B., and Meglio, M. (1996). Cerebral blood flow velocities and trigeminal ganglion stimulation. A transcranial Doppler study. Stereotact. Funct. Neurosurg. 66, 184-192. doi: 10.1159/000099687

Watson, P., Black, K. E., Clark, S. C., and Maughan, R. J. (2006). Exercise in the heat: effect of fluid ingestion on blood-brain barrier permeability. Med. Sci. Sports Exerc. 38, 2118-2124. doi: 10.1249/01.mss.0000235356.31932.0a

Watson, P., Shirreffs, S. M., and Maughan, R. J. (2005). Blood-brain barrier integrity may be threatened by exercise in a warm environment. Am. J. Physiol. Regul. Integr. Comp. Physiol. 288, R1689-R1694. doi: 10.1152/ajpregu.00676.2004

White, M. D. (2006). Components and mechanisms of thermal hyperpnea. J. Appl. Physiol. 101, 655-663. doi: 10.1152/japplphysiol.00210.2006

Willie, C. K., Macleod, D. B., Shaw, A. D., Smith, K. J., Tzeng, Y. C., Eves, N. D., et al. (2012). Regional brain blood flow in man during acute changes in arterial blood gases. J. Physiol. 590, 3261-3275. doi: 10.1113/jphysiol.2012.228551

Willie, C. K., Tzeng, Y. C., Fisher, J. A., and Ainslie, P. N. (2014). Integrative regulation of human brain blood flow. J. Physiol. doi:10.1113/jphysiol.2013.268953
Wilson, T. E., Brothers, R. M., Tollund, C., Dawson, E. A., Nissen, P., Yoshiga, C. C., et al. (2009). Effect of thermal stress on Frank-Starling relations in humans. J. Physiol. 587, 3383-3392. doi: 10.1113/jphysiol.2009.170381

Wilson, T. E., Cui, J., and Crandall, C. G. (2002a). Effect of whole-body and local heating on cutaneous vasoconstrictor responses in humans. Auton. Neurosci. 97, 122-128. doi: 10.1016/S1566-0702(02)00046-2

Wilson, T. E., Cui, J., Zhang, R., and Crandall, C. G. (2006). Heat stress reduces cerebral blood velocity and markedly impairs orthostatic tolerance in humans. Am. J. Physiol. Regul. Integr. Comp. Physiol. 291, R1443-R1448. doi: 10.1152/ajpregu.00712.2005

Wilson, T. E., Cui, J., Zhang, R., Witkowski, S., and Crandall, C. G. (2002b). Skin cooling maintains cerebral blood flow velocity and orthostatic tolerance during tilting in heated humans. J. Appl. Physiol. 93, 85-91. doi: 10.1152/japplphysiol.01043.2001

Zapata, P., Larrain, C., Iturriaga, R., and Alcayaga, J. (1994). The carotid bodies as thermosensors: experiments in vitro and in situ, and importance for ventilatory regulation. Adv. Exp. Med. Biol. 360, 253-255. doi: 10.1007/978-14615-2572-1_40

Zheng, F., Sheinberg, R., Yee, M. S., Ono, M., Zheng, Y., and Hogue, C. W. (2013). Cerebral Near-Infrared Spectroscopy (NIRS) monitoring and neurologic outcomes in adult cardiac surgery patients and neurologic outcomes: a systematic review. Anesth. Analg. 116, 663-676. doi: 10.1213/ANE.0b013e318277a255

Conflict of Interest Statement: The authors declare that the research was conducted in the absence of any commercial or financial relationships that could be construed as a potential conflict of interest.

Received: 09 January 2014; accepted: 18 February 2014; published online: 04 March 2014.

Citation: Bain AR, Morrison SA and Ainslie PN (2014) Cerebral oxygenation and hyperthermia. Front. Physiol. 5:92. doi: 10.3389/fphys.2014.00092

This article was submitted to Integrative Physiology, a section of the journal Frontiers in Physiology.

Copyright (c) 2014 Bain, Morrison and Ainslie. This is an open-access article distributed under the terms of the Creative Commons Attribution License (CC BY). The use, distribution or reproduction in other forums is permitted, provided the original author(s) or licensor are credited and that the original publication in this journal is cited, in accordance with accepted academic practice. No use, distribution or reproduction is permitted which does not comply with these terms. 